\title{
Prophylactic health products use in Penaeus vannamei farming in Andhra Pradesh: Perception of shrimp farmers of north, central and south coastal regions
}

\author{
TOMS C. JOSEPH ${ }^{1}$, B. MADHUSUDANA RAO ${ }^{2}$, P. CHANDRA RAO ${ }^{2}$, K. S. BIBINDAS ${ }^{1}$, \\ T. R. LAKSHMI ${ }^{1}$, C. G. JOSHY ${ }^{1}$, MAHMOUD EL THOLTH ${ }^{3}$ AND FRANCIS J. MURRAY ${ }^{3}$ \\ ${ }^{I}$ ICAR-Central Institute of Fisheries Technology, Willingdon Island, Kochi - 682 029, Kerala, India \\ ${ }^{2}$ Visakhapatnam Research Centre of ICAR-Central Institute of Fisheries Technology, Visakhapatnam - 530003 \\ Andhra Pradesh, India \\ ${ }^{3}$ Institute of Aquaculture, University of Stirling, Stirling FK9 4LA, UK \\ e-mail: tomscjoseph@gmail.com
}

\begin{abstract}
Antibiotic residues in shrimp meat pose food safety threats and trade implications. Shrimp farmers employ prophylactic health products, commonly known as probiotics (gut, water and soil probiotics), to prevent disease occurrence thereby negating the need for the use of antibiotics in shrimp health management. Information on the use of probiotics, decision on probiotic selection and farming practices was elicited from 182 Penaeus vannamei shrimp farmers of Andhra Pradesh from four districts representing the north coastal (Srikakulam District), central coastal (East Godavari and West Godavari districts) and south coastal (Nellore District) districts, by questionnaire based survey. Majority of the farmers $(50 \%)$ used only one probiotic during the rearing of $P$. vannamei but $15 \%$ farmers used up to three probiotics. $P$. vannamei farmers used 45 different probiotics brands and the probiotic brand was mostly co-selected with the feed brand. Feed technician (employee of the feed manufacturer involved in marketing and promotion of feed) alone was responsible for the selection of the probiotic brand to be used by $52 \%$ of shrimp farmers in Srikakulam, $50 \%$ of shrimp farmers in East Godavari, $40 \%$ of shrimp farmers in West Godavari and 32\% of shrimp farmers in Nellore districts. More than $30 \%$ of the shrimp famers of West Godavari, Nellore and East Godavari took a neutral stance on the performance of the probiotic but were still using probiotics as a safety measure. The baseline data on prophylactic health products usage is the first step in understanding the dynamics of probiotic use and underlines the need for concerted research to assess the quality of these products (in terms of label claims) that are used by shrimp famers in significant quantities that profoundly influence the production cost.
\end{abstract}

Keywords: Penaeus vannamei, Probiotics, Prophylactic health products, Shrimp farmers

India exported 1.37 million $t$ of seafood valued at an all time high of US\$ 7.08 billion in 2017-18. Frozen shrimp constituted the major item of the total fishery export from India, both in terms of quantity $(41.1 \% ; 565,980 \mathrm{t})$ and export value (68.4\%; US\$ 4.85 billion). Till recently, frozen finfish was exported in larger quantities whereas frozen shrimp realised higher value. However, a sharp increase in the percentage share of frozen shrimp in the total fishery exports from India, both in terms of quantity and value is being observed since 2010 . The substantial increase in the quantity of frozen shrimp exports can be squarely attributed to the introduction of Pacific white shrimp, Penaeus vannamei in 2009-10 into India and its exponential farming by Indian farmers; especially by the farmers from Andhra Pradesh. The area under $P$. vannamei farming in India increased from 283 ha (2009-10) to 50,240.77 ha (2015-16) and in Andhra Pradesh the area under $P$. vannamei farming increased on similar lines; from 264 ha (2009-10) to 39,800 ha (2015-16). India's export production of $P$. vannamei increased from a mere $1,731 \mathrm{t}(2009-10)$ to $406,018 \mathrm{t}$ (2015-16) in a short span of seven years and has positively impacted the shrimp processing sector in Andhra Pradesh (Ashok et al., 2013).

Antibiotics find use in aquaculture for the prevention and treatment of aquatic animal diseases, mainly bacterial diseases. On the regulatory front, India has listed 20 antibiotics/pharmacologically active substances that are prohibited for use in shrimp aquaculture (GOI, 2002). The presence of residues of antibiotics or their metabolites in farmed shrimp are potentially harmful to the shrimp consumers and importing countries have reported the presence of antibiotic residues in farmed $P$. vannamei shrimp exported from India (Rao and Prasad, 2015). In an attempt to avoid the necessity of antibiotic use, shrimp farmers started relying on probiotics for shrimp health 
management. There is paucity of data on the shrimp farmers' attitude towards prophylactic health products and the present manuscript examines the perceptions of the shrimp farmers in four districts representing the north coastal, central coastal and south coastal regions of Andhra Pradesh.

Questionnaire based on-site survey was conducted in 2017 covering randomly selected 182 P. vannamei shrimp farmers located in four coastal districts of Andhra Pradesh (AP), India namely Srikakulam District $(n=50$; north coastal AP); East Godavari and West Godavari districts $(n=82$; central coastal AP) and Nellore District $(n=50$; south coastal AP), to elicit details pertaining to different probiotics applied, decision making on probiotic selection, farmers profile, from P. vannamei shrimp farmers in the selected regions. Numerical data collected from shrimp farm data was pooled district-wise and subjected to univariate analysis of variance (UNIANOVA) followed by post-hoc multi comparison employing Tukey's HSD to test significant difference $(\mathrm{p}<0.05)$. Assumptions such the distribution of farmers' opinion on probiotics efficacy, distribution of salinity, production, feed consumption, feed conversion ratio (FCR), shrimp price, median age of the farmers and median area of the shrimp farms across categories of districts were assumed as same. All the assumptions were tested and interpreted using the independent samples-Kruskal-Wallis Test. Asymptomatic differences in the medians of farmers' age and medians of farm area was tested employing the Independent samples Median test.

P. vannamei farming was carried out at wide range of salinities, varying from 4 to 45 ppt (Fig. 1) and salinity of shrimp rearing water is a discerning feature in the different shrimp farming regions of AP. Eighty six percent of the farmers in south coastal AP and $76 \%$ of farmers in north coastal AP were rearing P. vannamei at salinities above 20 ppt. On the contrary, the farmers in central coastal AP (East Godavari -96\% and West Godavari-78\%) were farming $P$. vannamei in relatively lower salinities $(<9 \mathrm{ppt})$. Between the districts, salinity of shrimp farms of East Godavari and West Godavari were not significantly different whereas shrimp farms in Srikakulam and Nellore districts were different from each other and also significantly different from East and West Godavari districts $(p<0.05)$. Growth and survival of $P$. vannamei juveniles was reported to be positively influenced by an increase of salinity from 4 to $32 \mathrm{ppt}$ (Maica et al., 2014). Growth of juvenile shrimp maintained at different salinities showed that growth was comparable to that of normal seawater in shrimp grown above 5 ppt salinity (Jayasankar et al., 2009). However, in the present survey, the distribution of shrimp production was found to be

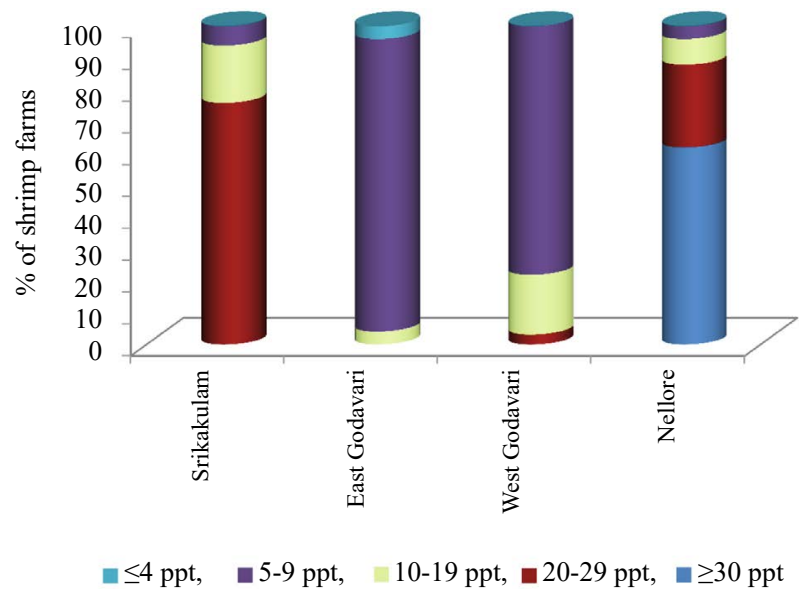

Fig. 1. Salinity of water used for P. vannamei shrimp rearing in north, central and south coastal Andhra Pradesh

Values expressed as percentage of shrimp farms. Srikakulam $(n=50)$, East Godavari $(n=50)$, West Godavari $(n=32)$, Nellore $(n=50)$ and Andhra Pradesh (n=182) farms

same across different ranges of salinities $(\mathrm{p}<0.05)$ which might be attributed to better management practices under all salinity ranges. The distribution of area of shrimp farms in East and West Godavari districts were significantly different $(p<0.05)$. Distribution of total feed consumption was also found different across different districts. Total feed consumption in shrimp farms of East Godavari and West Godavari were significantly different $(p<0.05)$. The FCR of shrimp farms in West Godavari was significantly different from East Godavari, Srikakulam and Nellore districts $(p<0.05)$. However, the distribution of shrimp price was same across categories of districts. The median age of farmers and the median area of shrimp farms were same across different districts.

Probiotics (including gut probiotics, water and soil bioremediators) are added to improve pond water quality and to enhance the shrimp health leading to better weight gain (Hai and Fotedar, 2010; Wang and Gu, 2010). Accumulation of waste in the form of unutilised feed and feed additives and faecal matter deteriorates pond water quality. Application of beneficial microorganisms in the form of water probiotics (bioremediators) degrades the waste and aids in improving pond water quality. Application of probiotics change the microbial species composition in aquaculture ponds and $80-100 \%$ survival of shrimp was achieved in aquaculture ponds treated with probiotics (Moriarty, 1999). Rico et al. (2013) observed the use of probiotics in $91 \%$ of shrimp farms in Vietnam and $74 \%$ shrimp farms in Thailand. In the present study, $100 \%$ of the $P$. vannamei farmers surveyed in the four districts of AP used probiotics; a minimum 
of one probiotic and a maximum of three probiotics per shrimp farm. The farmers were predominantly using only one probiotic during the rearing of $P$. vannamei in West Godavari (62.5\%), Srikakulam (50\%), East Godavari $(48 \%)$ and Nellore (44\%). However, use of two probiotics during the culture period was more frequent in Nellore (44\%) and East Godavari (42\%). Farms employing three probiotics were relatively more common in Srikakulam $(26 \%)$. A total of 45 different brands of probiotics were being used by the shrimp farmers in the surveyed regions of AP. Maximum number of probiotic brands were used in East Godavari (26) followed by West Godavari (21), Srikakulam (18) and Nellore (16). However, two probiotics (Probiotic-A and Probiotic-B) were predominantly used by relatively large number of $P$. vannamei farmers in all the four districts; ranging from 42.1 (Srikakulam) to $46.4 \%$ (Nellore). Probiotic-A was relatively preferred in West Godavari (31.3\%) and Nellore (36.9\%) while probiotic-B was preferred in Srikakulam (23.9\%) and East Godavari $(25 \%)$ districts.

Regular use of prophylactic health products on the shrimp farm incurs cost to the farmers but several people were actively involved in influencing the selection of probiotic by the shrimp farmer. Feed technician (employee of the feed manufacturer involved in marketing and promotion of feed), lab technician (person involved in testing of water parameters and suggest remedies), chemical technician (person other than the feed technician involved in marketing chemicals, disinfectants, sanitisers) and peer farmers (shrimp farmers of same or adjoining villages) influenced the farmer in choosing a particular feed brand. Out of all, feed technician alone is responsible for deciding the brand of probiotic to be used in $52 \%$ of shrimp farms in Srikakulam, 50\% of shrimp farms in East Godavari, $40 \%$ of shrimp farms in West Godavari and $32 \%$ of shrimp farms in Nellore districts (Fig. 2). An important observation was that feed technician along with others, without the involvement of the farmers, were responsible for probiotic selection by 76, 64, 58 and 46\% of shrimp farmers in Nellore, East Godavari, Srikakulam and West Godavari districts respectively. The survey clearly indicated that the deciding power greatly rests in the hands of the feed technician.

Majority of the shrimp farmers from Srikakulam (76\%), West Godavari (66\%), East Godavari (60\%) and Nellore $(52 \%)$ districts were either satisfied or very satisfied with the performance of the probiotics used by them (Table 1). The distribution of farmers' opinion on performance of probiotics was not significantly different. However, more than $30 \%$ of the farmers of West Godavari, Nellore and East Godavari took a neutral viewpoint on the performance of probiotics. Lakshmi et al. (2017) examined 58 prophylactic health products sold in Andhra Pradesh for P. vannamei shrimp farming and reported that $41 \%$ of the products displayed microbial count and microbial composition on the label, $17 \%$ had only microbial count, $16 \%$ had microbial composition only while $26 \%$ of the products did not provide any information regarding the microbial count and composition. It is pertinent to note that only $22 \%$ of the probiotics had microbial count as claimed on the label.

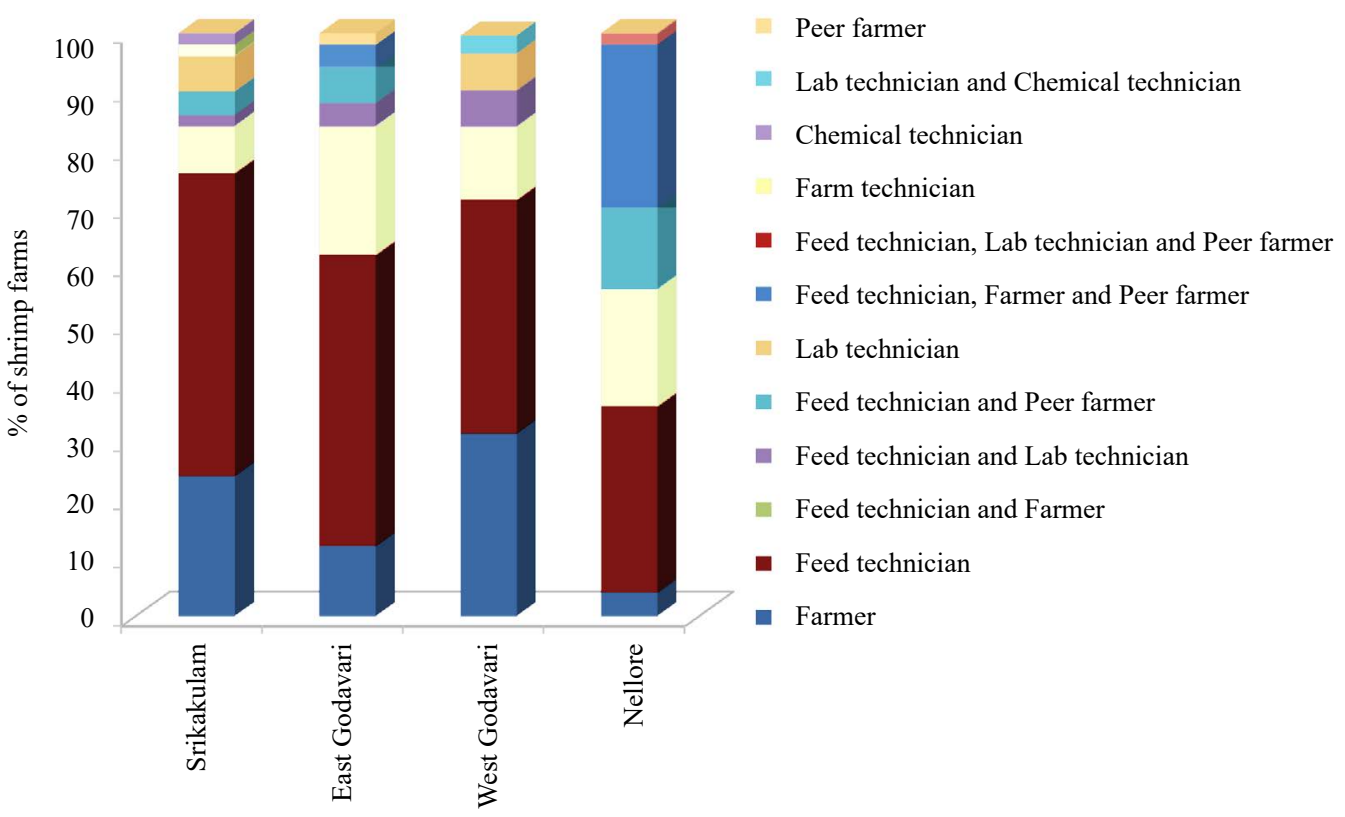

Fig. 2. Persons influencing decision making on probiotic brand selection in P. vannamei farms of Andhra Pradesh 
Table 1. Opinion of the shrimp farmers of Andhra Pradesh regarding the performance of probiotics

\begin{tabular}{lllll}
\hline Opinion & Srikakulam (\%) & East Godavari (\%) & West Godavari (\%) & Nellore (\%) \\
\hline Very dissatisfied & 0 & 6 & 0 & 12 \\
Dissatisfied & 2 & 4 & 0 & 4 \\
Neutral & 22 & 30 & 34.4 & 32 \\
Satisfied & 40 & 38 & 34.4 & 44 \\
Very satisfied & 36 & 22 & 31.3 & 8 \\
\hline
\end{tabular}

Forty five varieties of probiotics were being used in $P$. vannamei shrimp farming in the surveyed areas. The dose of probiotic to be applied per hectare, based on label instructions, varied between 0.25 and $15 \mathrm{~kg}$ with a median dose of $1.25 \mathrm{~kg}$ and the label price of probiotic per $\mathrm{kg}$ varied between ₹145 and ₹7,000 with a median price of $₹ 1,784$. The total dose of probiotic required for 12 week application per hectare ranged from 3 to $180 \mathrm{~kg}$ with a median of $15 \mathrm{~kg}$ (assuming that the shrimp farmer applies the probiotic for 12 weeks of rearing period) incurring $₹ 4,350$ to $₹ 94,500$ with a median cost of ₹26,730 towards the cost of probiotics.

Probiotic brand-A was commonly used by farmers of Nellore (36.9\%) and West Godavari (31.3\%) districts while the farmers of East Godavari $(25 \%)$ and Srikakulam $(23.9 \%)$ districts preferred probiotic brand-B. Probiotic brand-A was distributed by the manufacturer of Feed-A and probiotic brand-B was supplied by the manufacturer of Feed-B. Feed brand-A was preferred in Nellore and West Godavari districts and Feed brand-B was preferred in East Godavari and Srikakulam districts. The survey indicates that the deciding power greatly rests in the hands of the feed technician and once the feed brand was selected by the farmer, there is maximum possibility of the farmer ending up using the probiotics supplied by the same feed manufacturer (Fig. 3). Educational background might have had a profound influence on the decision making of the shrimp farmer. This is strengthened by the observation

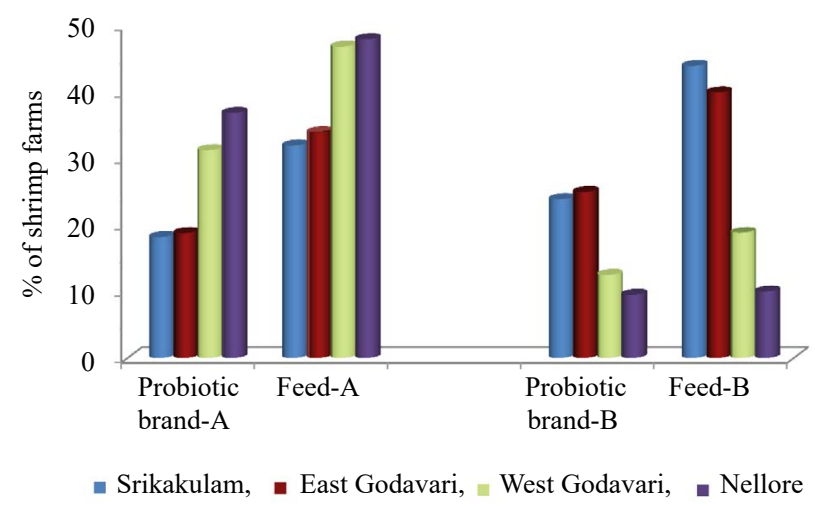

Fig. 3. Pattern of co-selection of probiotic brand and feed brand by $P$ vannamei farmers in different regions of Andhra Pradesh that the decision to select a particular feed brand, solely by the feed technician without the farmer's involvement was maximum in Srikakulam (44\%) compared to the other districts (0 to $16 \%$ ). The formal education level of the shrimp farmers was less than $12^{\text {th }}$ grade in Srikakulam $(86 \%)$ and farmers who had completed graduation were relatively lower in Srikakulam (6\%). Lekshmi et al. (2005) observed that information seeking behaviour, credit orientation and material possession were found to influence the extent of adoption of shrimp culture technologies by shrimp famers.

Prophylactic health products were being regularly used by the shrimp farmers of Andhra Pradesh in significant quantities that profoundly influences the production cost. Feed technician was the major player influencing the shrimp farmers in the decision making process for selecting probiotics. Probiotic brand is being co-selected along with the particular feed brand. However, more than $30 \%$ of the famers of West Godavari, Nellore and East Godavari districts of AP took a neutral viewpoint (i.e. neither good nor bad) on the performance of the probiotic but were still using them. Concerted efforts are needed to assess the microbiological quality and performance of the prophylactic health products in terms of product label claims to instill farmers' confidence.

\section{References}

Ashok, A., Murthy, L. N., Rao, B. M, Debbarma, J., Prasad, M. M., Geethalakshmi, V. and Gopal, N. 2013. Impact of Pacific white shrimp (Litopenaeus vannamei) on shrimp production and seafood processing in Andhra Pradesh. Fish. Technol., 52 : 53-57.

GOI 2002. The Gazette of India Extraordinary, Order No.729 (E),10 July 2002, Ministry of Commerce and Industry, Government of India.

Hai, N. V. and Fotedar, R. 2010. A review of probiotics in shrimp aquaculture. J. Appl. Aquac., 22: 251-266. https://doi.org/10. 1080/10454438.2010.500597.

Jayasakar, V., Jasmani, S., Nomura, T., Nohara, S., Huong, D. T. T. and Wilder, M. N. 2009. Low salinity rearing of pacific white shrimp Litopenaeus vannamei: Acclimation, survival and growth of post-larvae and juveniles. JARQ, 43: 345-350.

Lakshmi, T. R., Bibindas, K. S., Madhusudana Rao, B. and Toms C. Joseph 2017. Microbial assessment of aquaculture probiotics sold in Indian market. In: Saly Thomas, N., 
Rao, B. M., Madhu, V. R., Asha, K. K., Binsi, P. K., Viji, P., Sajesh, V. K. and Jha, P. N. (Eds.), Book of Abstracts. Fostering Innovations in Fisheries and Aquaculture: Focus on sustainability and safety. $11^{\text {th }}$ Indian Fisheries and Aquaculture Forum, ICAR-Central Institute of Fisheries Technology, Kochi and Asian Fisheries Society Indian Branch, Mangalore, 21-24 November 2017, Kochi, India, p. 304.

Lekshmi, P. S. S., Chandrakandan, K., Kumaran, M. and Balasubramani, N. 2005. Socio-economic profile of shrimp farmers and its influence on the extent of adoption of shrimp culture technologies. Fish. Technol., 42: 225-230.

Maica, P. F., de Borba, M. R., Martins, T. G. and Junior, W. W. 2014. Effect of salinity on performance and body composition of Pacific white shrimp juveniles reared in a super-intensive system. R. Bras. Zootec., 43: 343-350. http://dx.doi.org/10.1590/S1516-359820140007 00001.

Moriarty, D. J. W. 1999. Disease control in shrimp aquaculture with probiotic bacteria. Microbial biosystems: New frontiers. In: Bell, C. R., Brylinsky, M., Johnson and Green, P. (Eds.), Proceedings of the $8^{\text {th }}$ International Symposium on Microbial ecology, Atlantic Canada Society for Microbial Ecology, Halifax, Canada.

Ro, B. M. and Prasad, M. M. 2015. Residues of veterinary medicinal products (antibiotics) in shrimp exported from India to the European Union (EU): Trends in the last decade. Fishing Chimes, 34: 6-11.

Rico, A., Phu, T., Satapornvanit, K., Min, J., Shahabuddin, A. M., Henriksson, P. J. G., Murray, F. J., Little, D. C., Dalsgaard, A. and Van den Brink, P. J. 2013. Use of veterinary medicines, feed additives and probiotics in four major internationally traded aquaculture species farmed in Asia. Aquaculture, 412-413: 231-243. https://doi.org/10.1016/j. aquaculture.2013.07.028

Wang, Y. and Gu, Q. 2010. Effect of probiotics on white shrimp (Penaeus vannamei) growth performance and immune response. Mar. Biol. Res., 6: 327-332. https://doi. org/10.1080/1745 1000903300893.

Date of Receipt $\quad$ :06.04.2019

Date of Acceptance : 08.04.2021 